\title{
Yttrium doped ZnO nanoparticles towards corrosion protection epoxy nanocomposite coatings in neutral and acidic medium
}

Johnkennadyvethanathan S ( $\sim$ johnkennadyvethanathan@gmail.com )

St John's College Palayamkottai https://orcid.org/0000-0003-2957-1467

Aboorvakani R

Madhu K.U.

\section{Research Article}

Keywords: Epoxy, Anticorrosion, Antibacterial, Chemical precipitation

Posted Date: February 24th, 2022

DOI: https://doi.org/10.21203/rs.3.rs-1382029/v1

License: (c) (i) This work is licensed under a Creative Commons Attribution 4.0 International License. Read Full License 


\section{Abstract}

In the present study, synthesized pure and Yttrium $(0.5,1.0,1.5,2.0$ and $2.5 \mathrm{mM})$ doped Zinc Oxide (YZO) nanoparticles by chemical precipitation method. The size effect of Zinc oxide nanoparticle under Yttrium acetate precursor molar concentration were investigated by various characterization techniques. X-ray diffractogram asserts the hexagonal wurtzite structure of ZnO nanoparticles. The average crystallite size was found to be $22-17 \mathrm{~nm}$. The FTIR and Raman spectrum inscribed the chemical composition and vibrational frequencies of the synthesized samples. The hexagonal shape, surface morphology, particle size and elemental composition of the samples were analysed by FESEM, HRTEM and EDAX. The optical bandgap energy was estimated in the range of 3.148-3.175 eV. PL spectra of yttrium doped ZnO nanoparticles at various concentration exhibit a strong UV emission band and green emission band. The anticorrosive property of nanoscopic size (17 nm) YZO/epoxy nanocomposite was studied by electrochemical impedance spectroscopy (EIS) technique in both neutral and acidic medium. Epoxy/YZO nanocomposites were prepared using different loadings $(0.05,0.10$ and 0.15 wt \%) of yttrium doped ZnO nanoparticles. Epoxy/YZO nanocomposites were applied on mild steel substrates. The acquisition of yttrium doped ZnO into the plain epoxy coating materially increased the charge transfer resistance $\mathrm{R}_{\mathrm{ct}}$ by 3.5 times in oxalic acid solution as against epoxy/ZnO coating. The synthesized sample has also displayed excellent antimicrobial activity against gram positive and gram-negative bacteria. This encapsulates that the YZO nanoparticles are a potential eco-friendly, antibacterial and anti-corrosive fillers in coat on mild steel.

\section{Full Text}

This preprint is available for download as a PDF.

\section{Tables}

Table 1: Structural parameters of $\mathrm{ZnO}$ nanoparticles and $\mathrm{Y}$ doped $\mathrm{ZnO}$ nanoparticles: Standard JCPDS Card no. (361451) $a=3.249 \AA$ and $c=5.206 \AA$

\begin{tabular}{|c|c|c|c|c|c|c|c|c|c|}
\hline \multirow[t]{2}{*}{$\begin{array}{l}\text { Y dopant } \\
\text { concentration }\end{array}$} & \multirow{2}{*}{$\begin{array}{l}\text { Average } \\
\text { crystalline } \\
\text { size D } \\
(\mathrm{nm})\end{array}$} & \multicolumn{2}{|c|}{$\begin{array}{l}\text { Lattice } \\
\text { parameter }\end{array}$} & \multirow{2}{*}{$\begin{array}{l}\text { c/a } \\
\text { ratio }\end{array}$} & \multirow{2}{*}{$\begin{array}{l}\text { Unit } \\
\text { cell } \\
\text { volume } \\
\text { v }\end{array}$} & \multirow{2}{*}{$\begin{array}{l}\text { Crystallite } \\
\text { volume } \\
(\mathrm{D})^{3} \\
(\mathrm{~nm})^{3}\end{array}$} & \multirow{2}{*}{$\begin{array}{l}\text { Micro } \\
\text { strain } \\
\varepsilon \\
\times 10^{-3}\end{array}$} & \multirow{2}{*}{$\begin{array}{l}\text { Bond } \\
\text { length } \\
(\mathrm{Zn}-0) \\
(\AA)\end{array}$} & \multirow{2}{*}{$\begin{array}{l}\text { Degree } \\
\text { of } \\
\text { distortion } \\
\mathrm{R}\end{array}$} \\
\hline & & $\mathrm{a}(\AA)$ & $c(\AA)$ & & & & & & \\
\hline $0.00 \mathrm{mM}$ & 22.78 & 3.2335 & 5.1918 & 1.6056 & 47.010 & 1.1838 & 1.1944 & 1.9695 & 1.0170 \\
\hline $0.50 \mathrm{mM}$ & 26.38 & 3.2494 & 5.2069 & 1.6024 & 47.611 & 1.8370 & 1.2990 & 1.9776 & 1.0190 \\
\hline $1.00 \mathrm{mM}$ & 23.40 & 3.2479 & 5.2047 & 1.6024 & 47.548 & 1.2818 & 1.4646 & 1.9767 & 1.0190 \\
\hline $1.50 \mathrm{mM}$ & 23.11 & 3.2511 & 5.2069 & 1.6015 & 47.661 & 1.2345 & 1.4831 & 1.9783 & 1.0196 \\
\hline $2.00 \mathrm{mM}$ & 17.61 & 3.2526 & 5.2156 & 1.6035 & 47.786 & 5.4610 & 1.7298 & 1.9800 & 1.0183 \\
\hline $2.50 \mathrm{mM}$ & 37.60 & 3.2432 & 5.1977 & 1.6026 & 47.346 & 5.3180 & 0.9115 & 1.9739 & 1.0189 \\
\hline
\end{tabular}

Table 2: EIS and corrosion parameters for YZO/epoxy coated mild steel in $3 \% \mathrm{NaCl}$ solution after 2 hours immersion 


\begin{tabular}{llclll} 
S.No & Materials & $\mathrm{R}_{\mathrm{ct}}$ & $-\mathrm{E}_{\text {corr }}$ & $\mathrm{I}_{\text {corr }}\left(\mathrm{mA} / \mathrm{cm}^{2}\right)$ & Corrosion rate (mm/year) \\
& & $(\mathbf{\Omega})$ & $(\mathrm{mV})$ & & \\
\hline 1. & $\mathrm{A}(0.05 \mathrm{wt} \% \mathrm{YZO})$ & 1289 & 533.640 & 10.272 & 0.000119 \\
\hline 2. & $\mathrm{B}(0.10 \mathrm{wt} \% \mathrm{YZO})$ & 7734 & 388.052 & 05.114 & 0.0000594 \\
\hline 3. & $\mathrm{C}(0.15 \mathrm{wt} \% \mathrm{YZO})$ & 3289 & 644.682 & 08.353 & 0.0000970
\end{tabular}

Table 3: EIS and corrosion parameters for Epoxy-ZnO/YZO coated mild steel in 3\% oxalic acid solution after 2 hours immersion

\begin{tabular}{llclll} 
S.No & Materials & $\mathbf{R}_{\mathrm{ct}}$ & $\begin{array}{l}-\mathrm{E}_{\text {corr }} \\
(\Omega)\end{array}$ & $\mathrm{I}_{\text {corr }}\left(\mathrm{mA} / \mathrm{cm}^{2}\right)$ & Corrosion rate $(\mathrm{mm} / \mathrm{mear})$ \\
\hline 1. & Epoxy-ZnO & 1424 & 498.223 & 13.951 & 0.00016 \\
\hline 2. & Epoxy-YZO & 4970 & 444.154 & 07.804 & 0.0000906
\end{tabular}

Table 4: Comparison of the corrosion parameters of different nanomaterial coating

\begin{tabular}{|c|c|c|c|c|c|}
\hline Sample & Substrate & Medium & $\begin{array}{l}-E_{\text {corr }} \\
(V)\end{array}$ & $\begin{array}{l}\mathrm{I}_{\text {corr }} \\
\left(\mu \mathrm{A} / \mathrm{cm}^{2}\right)\end{array}$ & Reference \\
\hline Graphene oxide & Mild steel & $\begin{array}{l}3.5 \mathrm{wt} \% \mathrm{NaCl} \\
\text { solution }\end{array}$ & 0.455 & 0.22 & [57] \\
\hline Titanium nanoparticle & Mild steel & $1 \mathrm{M} \mathrm{HCl}$ & 0.522 & 58.6 & [75] \\
\hline $\begin{array}{l}\mathrm{CeO}_{2} \text { doped } \mathrm{ZnO} \text { nanoparticles } \mathrm{Zn} \text { - } \\
\text { composite coating }\end{array}$ & Mild steel & $\begin{array}{l}3.5 \mathrm{wt} \% \mathrm{NaCl} \\
\text { solution }\end{array}$ & 1.093 & 0.1040 & [76] \\
\hline ZnO nanoparticles & $\begin{array}{l}\text { Stainless steel } \\
316 \mathrm{~L}\end{array}$ & Mild steel & 0.33815 & 2.28 & [77] \\
\hline $\begin{array}{l}\text { Zn-1\% Mn doped TiO2 nanoparticle } \\
\text { composite }\end{array}$ & Mild steel & Mild steel & 0.961 & 5.154 & [78] \\
\hline $\begin{array}{l}\mathrm{CSA} \text { doped polyaniline } \mathrm{SnO}_{2} \\
\text { nanocomposite }\end{array}$ & $\begin{array}{l}\text { A-36 Carbon } \\
\text { steel }\end{array}$ & $1 \mathrm{M} \mathrm{HCl}$ & 0.271 & 0.0048 & [79] \\
\hline Yttrium doped ZnO nanoparticles & Mild steel & Oxalic acid & 4.441 & 0.0078 & $\begin{array}{l}\text { Present } \\
\text { study }\end{array}$ \\
\hline
\end{tabular}

\section{Figures}



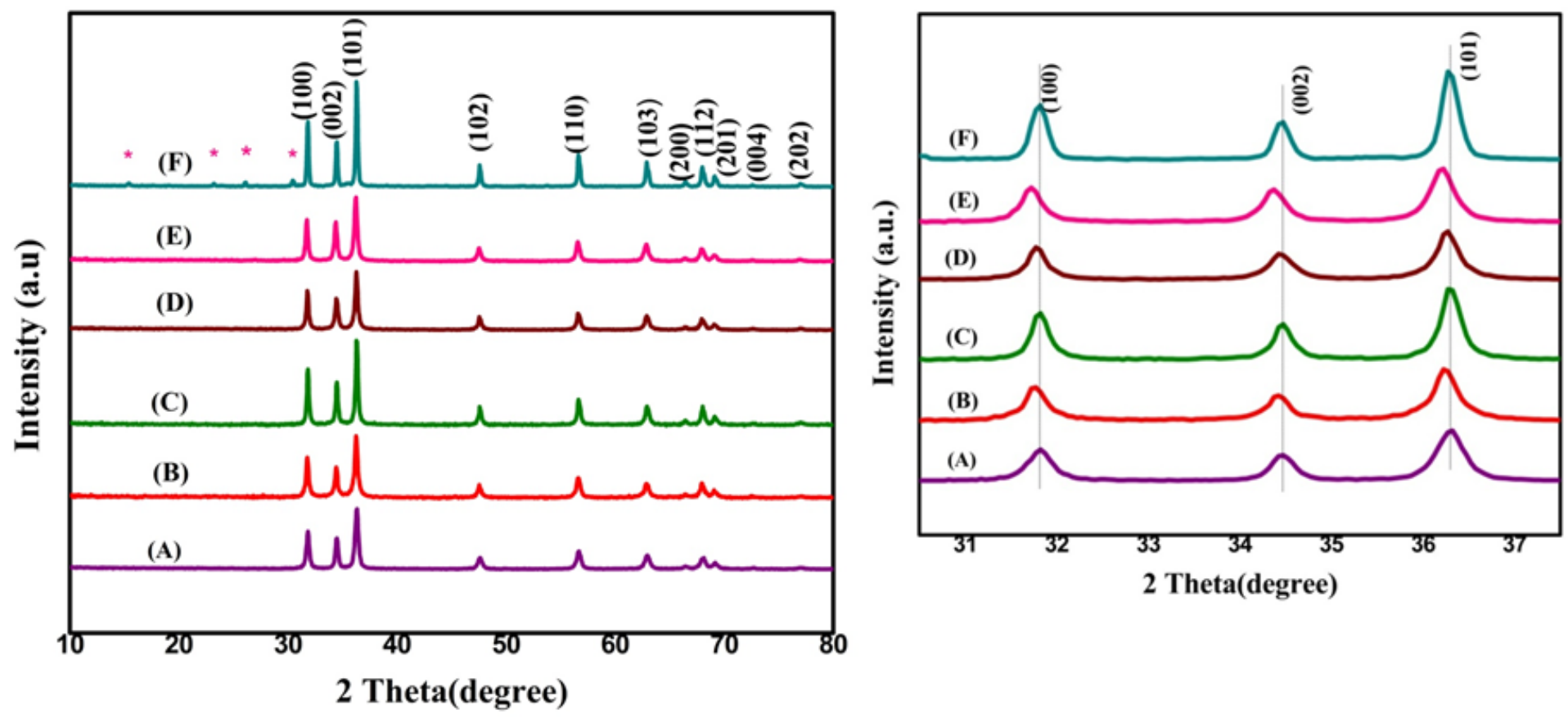

Figure 1

a (A-F) Typical XRD patterns of rare earth element (REE) yttrium $(0.0,0.5,1.0,1.5,2.0$ and $2.5 \mathrm{mM})$ doped ZnO nanoparticles

b (A-F) Diffraction peak broadening
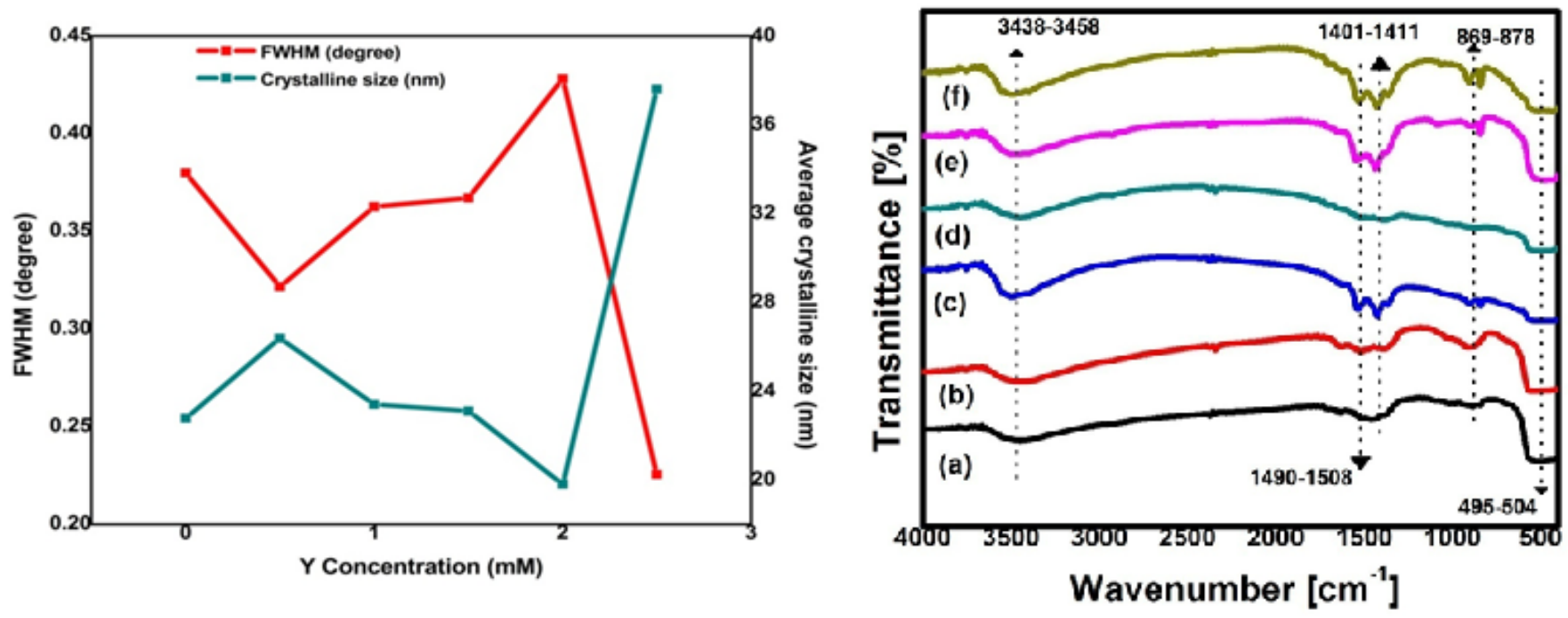

Figure 2

a Lattice parameter "a" and "c" values with various concentration of Yttrium

b The variation of full width half maximum (FWHM) and average crystalline size of yttrium $(0.0,0.5,1.0,1.5,2.0$ and $2.5 \mathrm{mM}$ ) doped $\mathrm{ZnO}$ nanoparticles as a function of $\mathrm{Y}$ concentration 


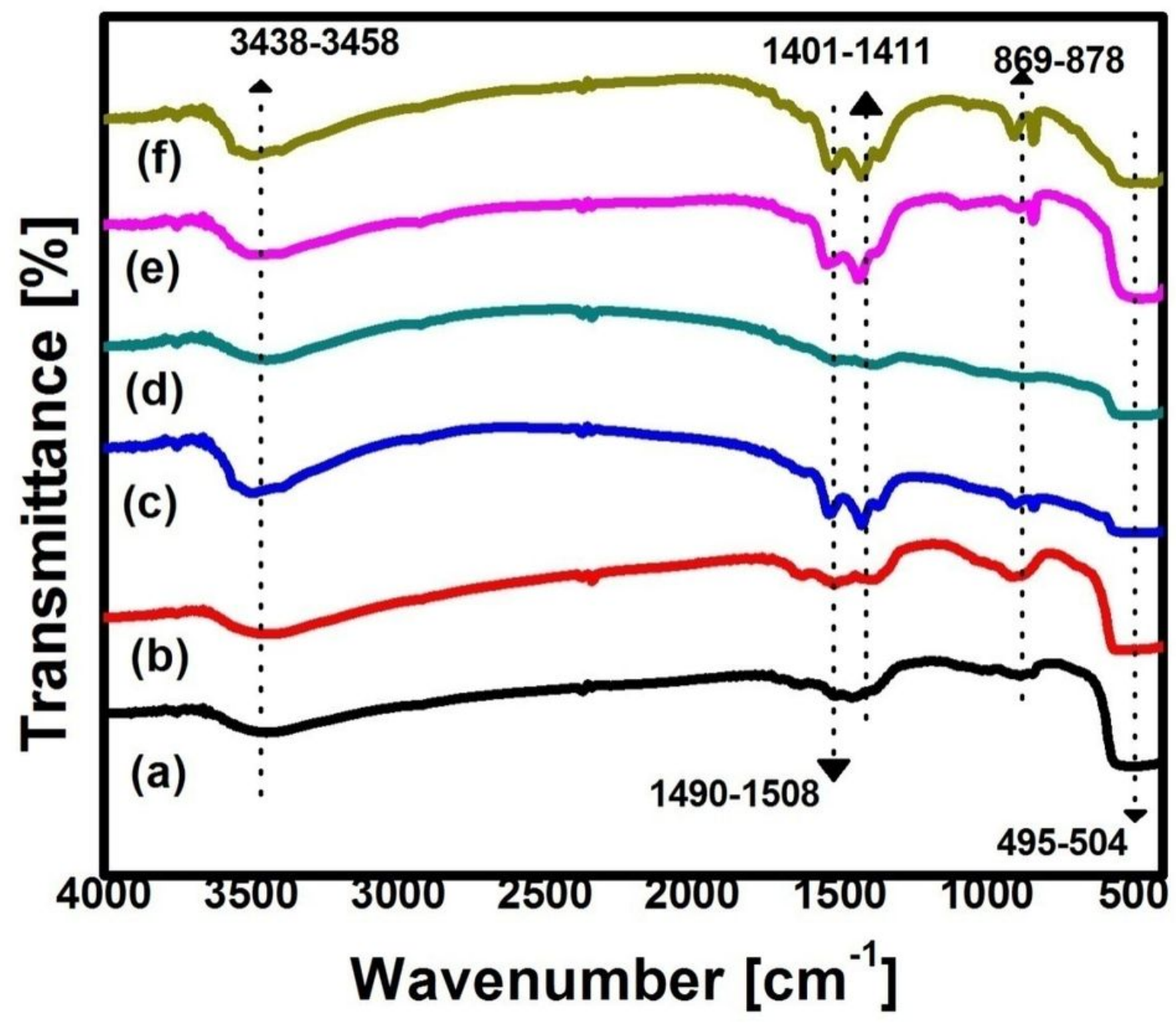

Figure 3

(A-F) FTIR spectra of yttrium $(0.0,0.5,1.0,1.5,2.0$ and $2.5 \mathrm{mM})$ doped ZnO nanoparticles 


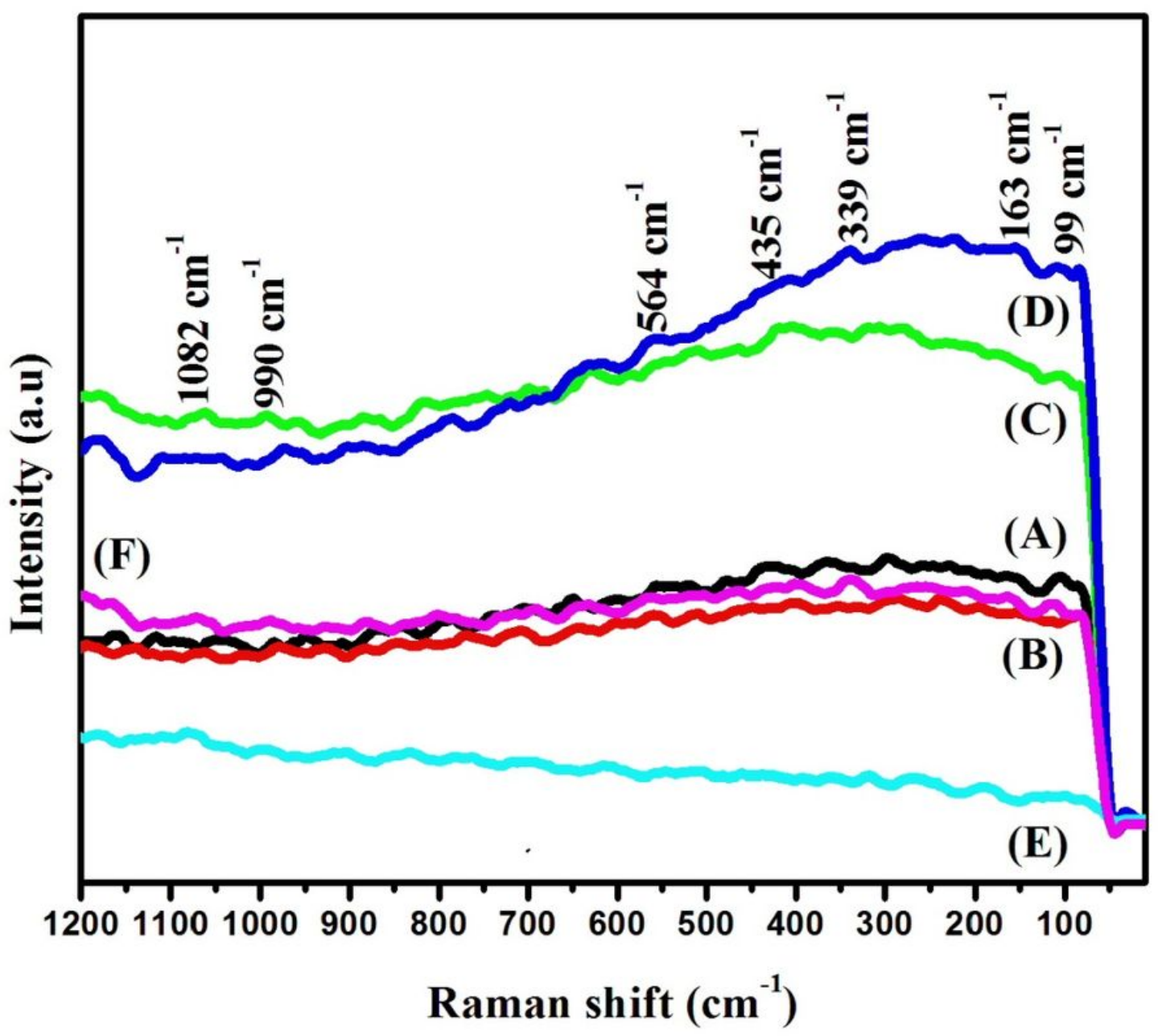

Figure 4

(A-F) FT-RAMAN spectra of yttrium $(0.0,0.5,1.0,1.5,2.0$ and $2.5 \mathrm{mM})$ doped $\mathrm{ZnO}$ nanoparticles 

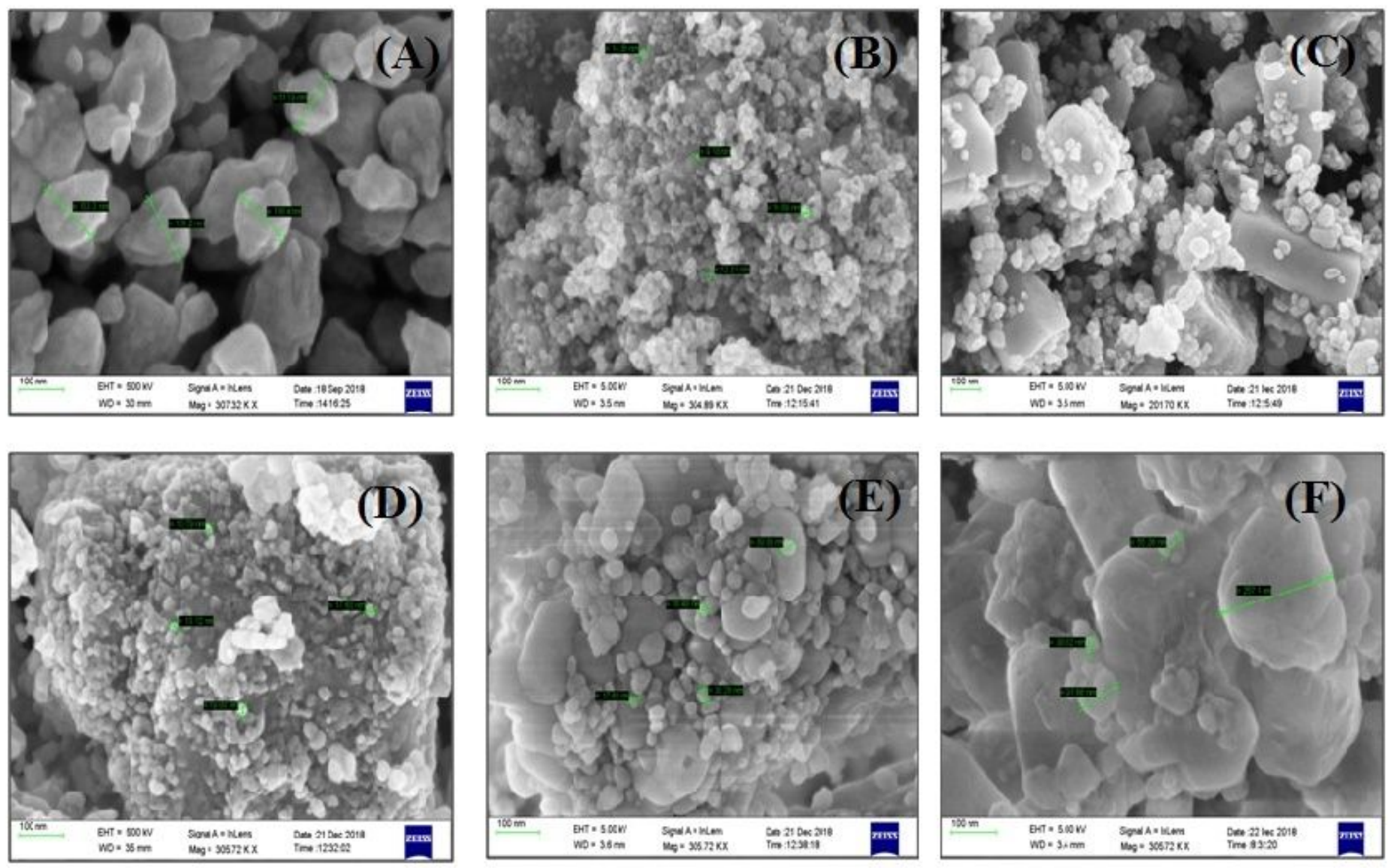

Figure 5

(A-F) FESEM images of yttrium $(0.0,0.5,1.0,1.5,2.0$ and $2.5 \mathrm{mM})$ doped $\mathrm{ZnO}$ nanoparticles 

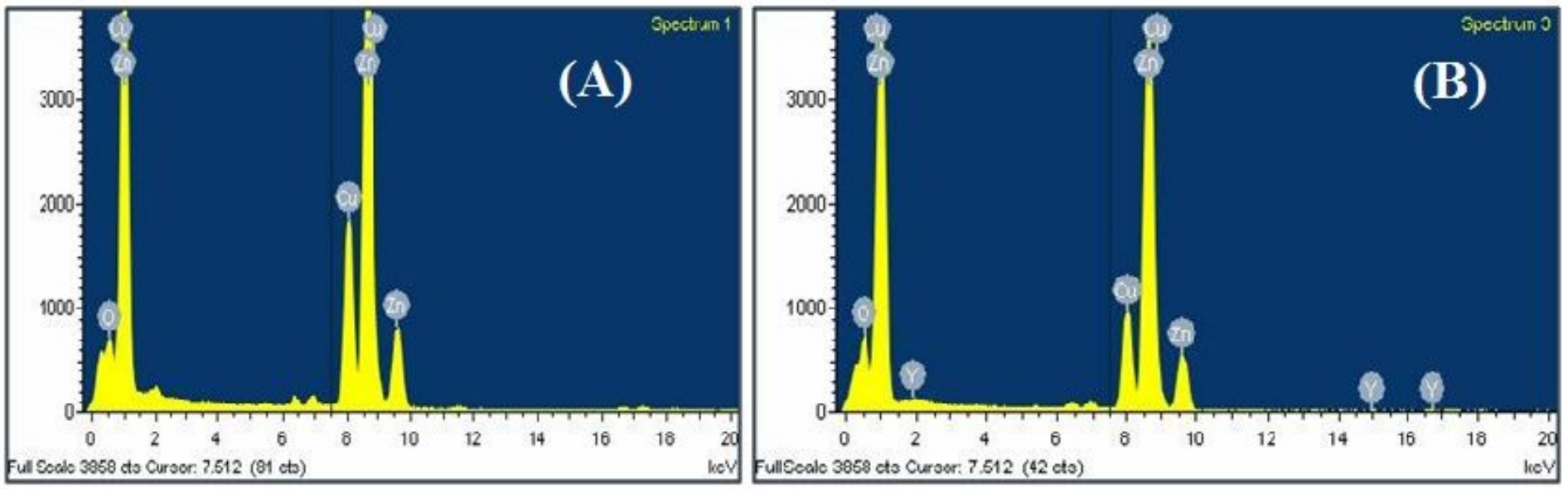

Figure 6

(A-B) EDAX spectrum of yttrium (0.0 and $2.0 \mathrm{mM})$ doped $\mathrm{ZnO}$ nanoparticles 


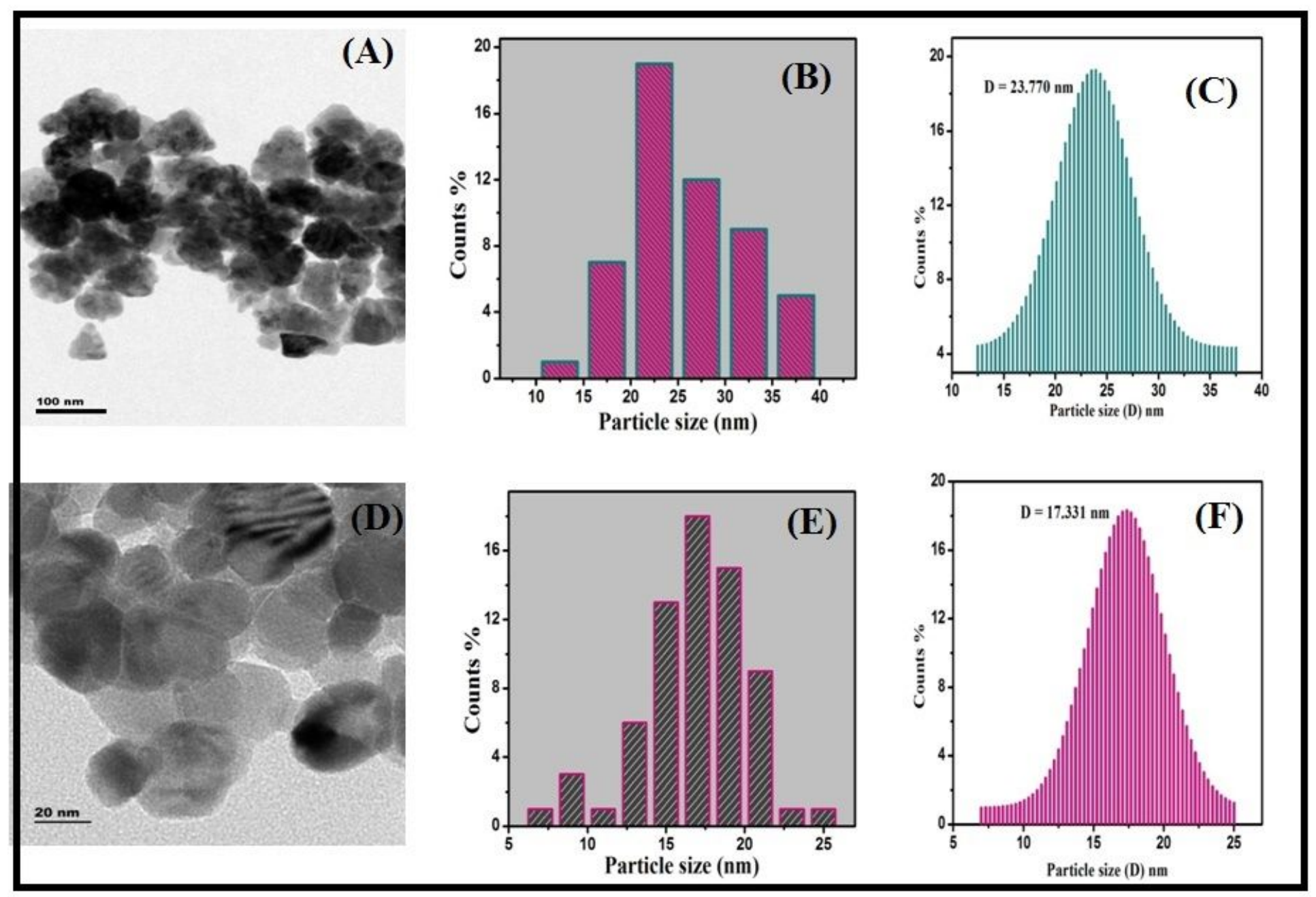

Figure 7

HRTEM images and particle size distribution histogram of (A-C) pure ZnO nanoparticles (D-F) yttrium $2.0 \mathrm{mM}$ doped ZnO nanoparticles 


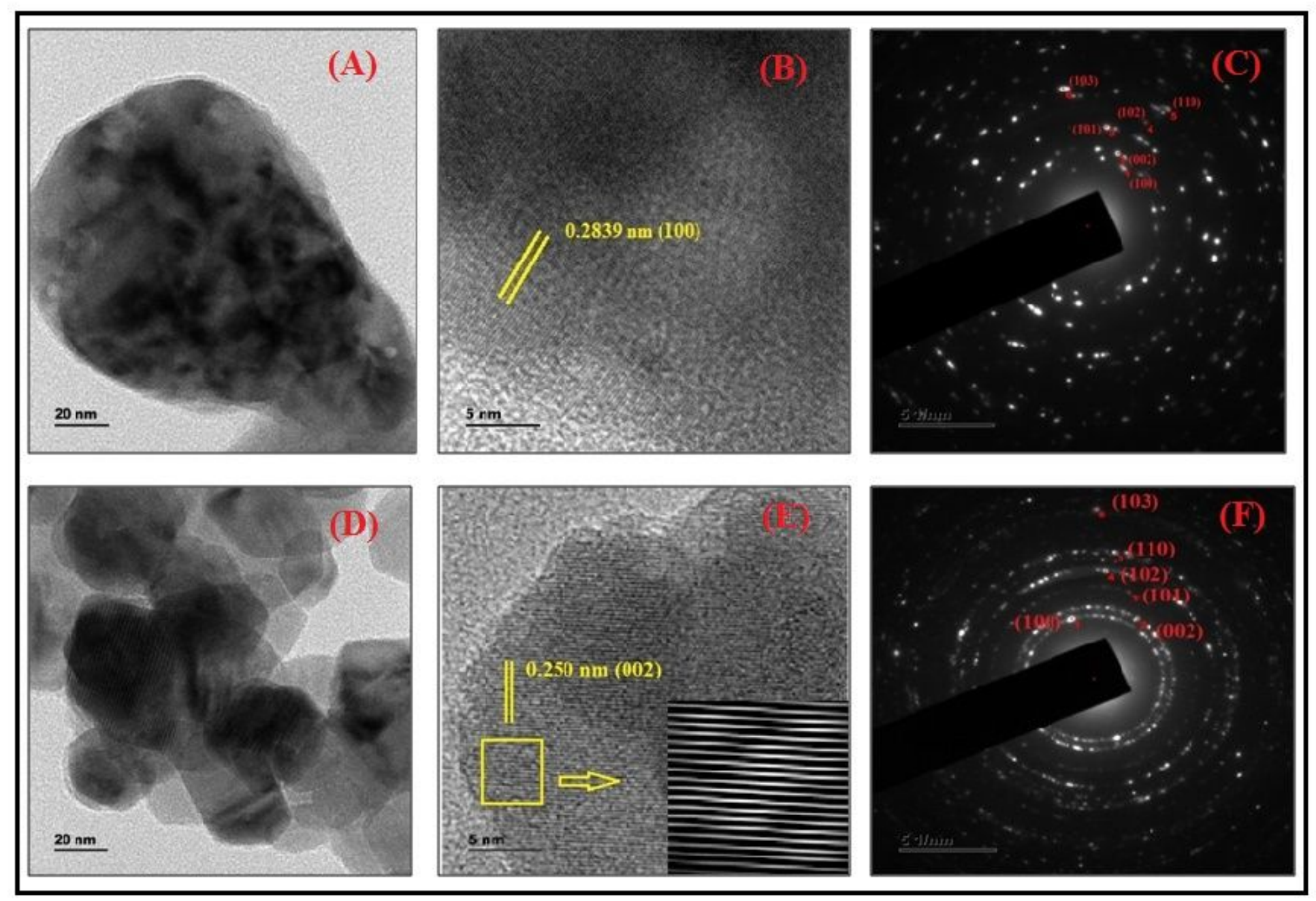

Figure 8

HRTEM image and interplanar lattice fringes and SAED pattern of (A-C) pure ZnO nanoparticles and (D-F) yttrium 2.0 $\mathrm{mM}$ doped $\mathrm{ZnO}$ nanoparticles 


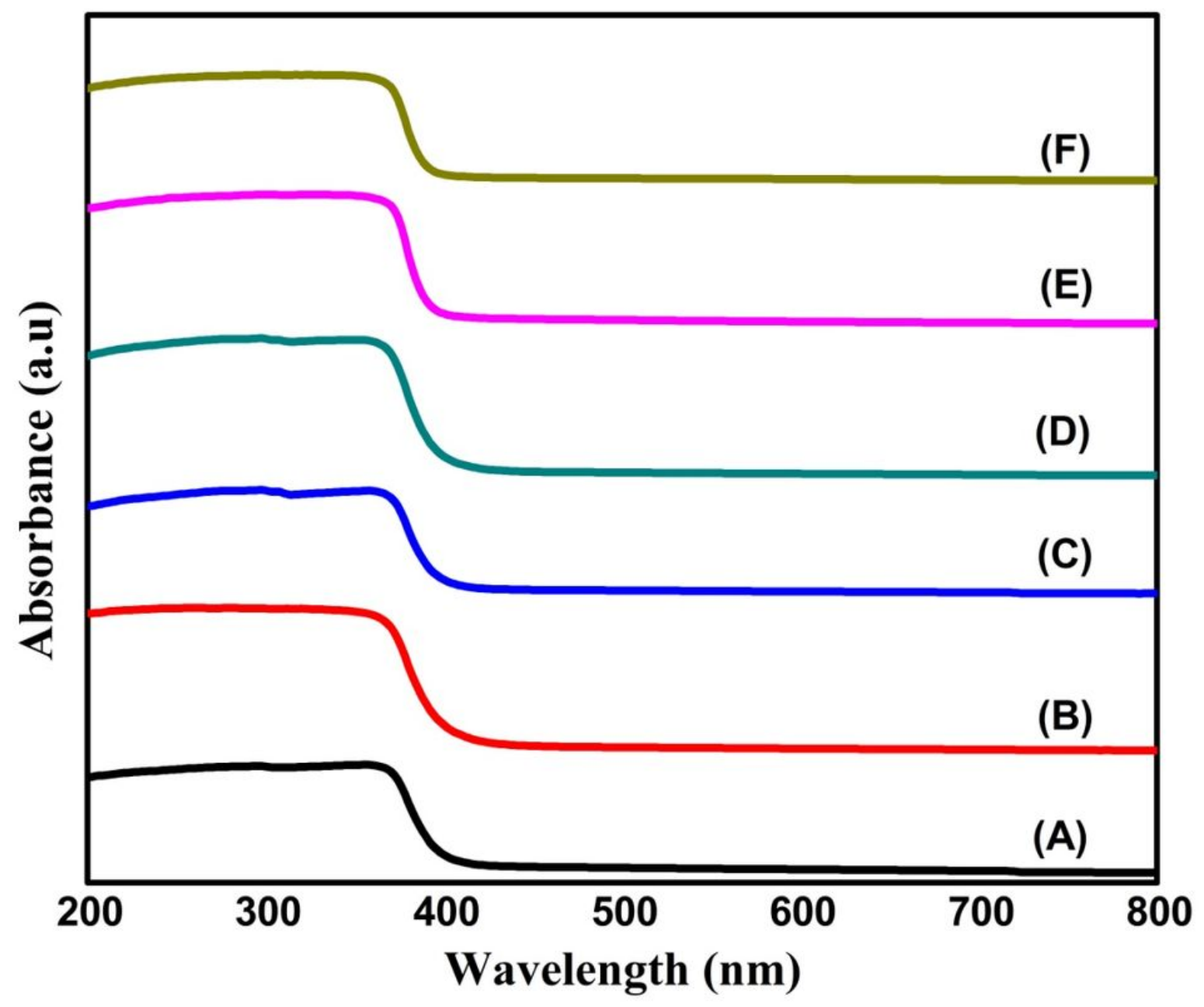

Figure 9

(A-F) UV-Visible absorption spectra of yttrium $(0.0,0.5,1.0,1.5,2.0$ and $2.5 \mathrm{mM})$ doped ZnO nanoparticles 


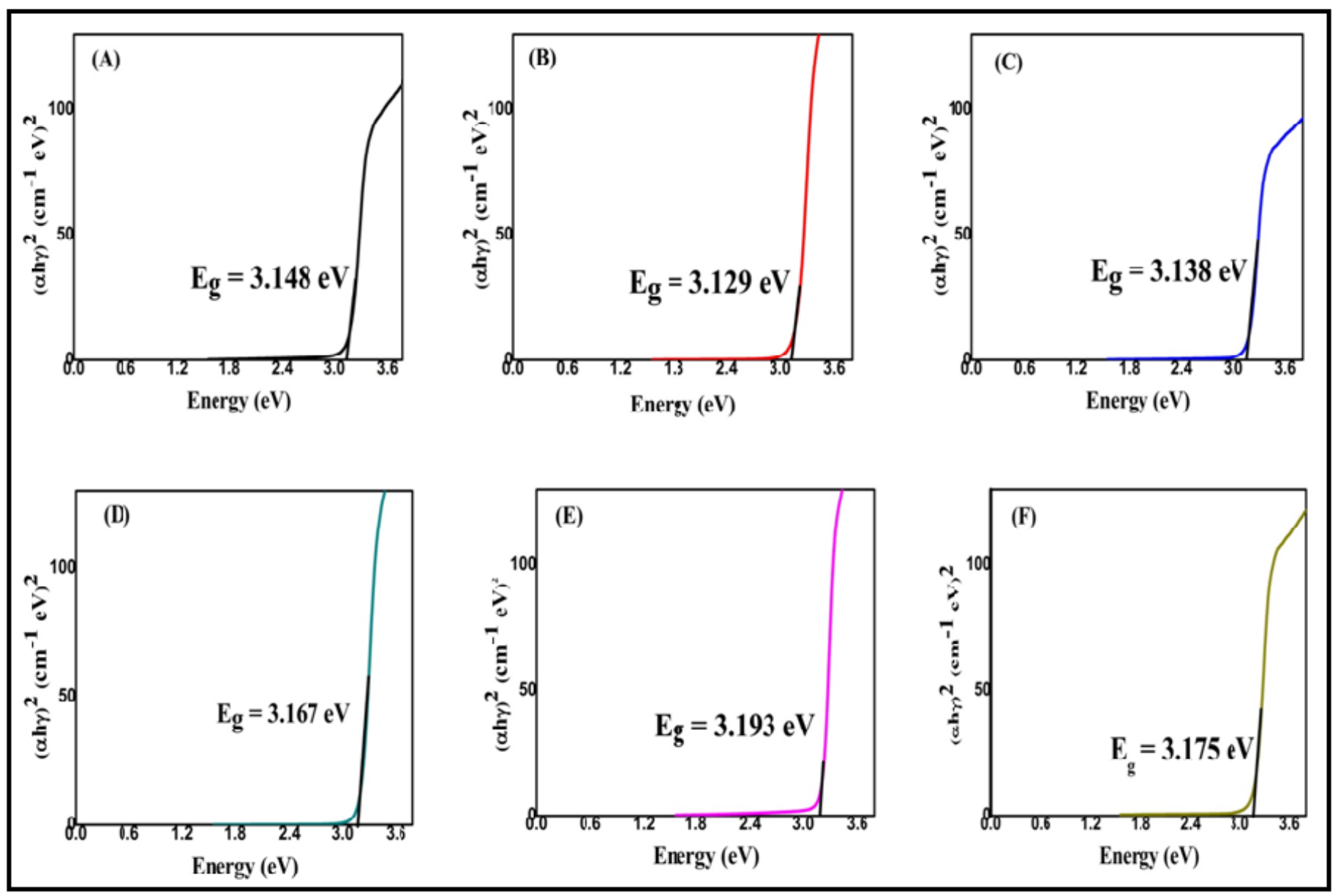

Figure 10

(A-F) Tauc plot of yttrium $(0.0,0.5,1.0,1.5,2.0$ and $2.5 \mathrm{mM})$ doped $\mathrm{ZnO}$ nanoparticles 


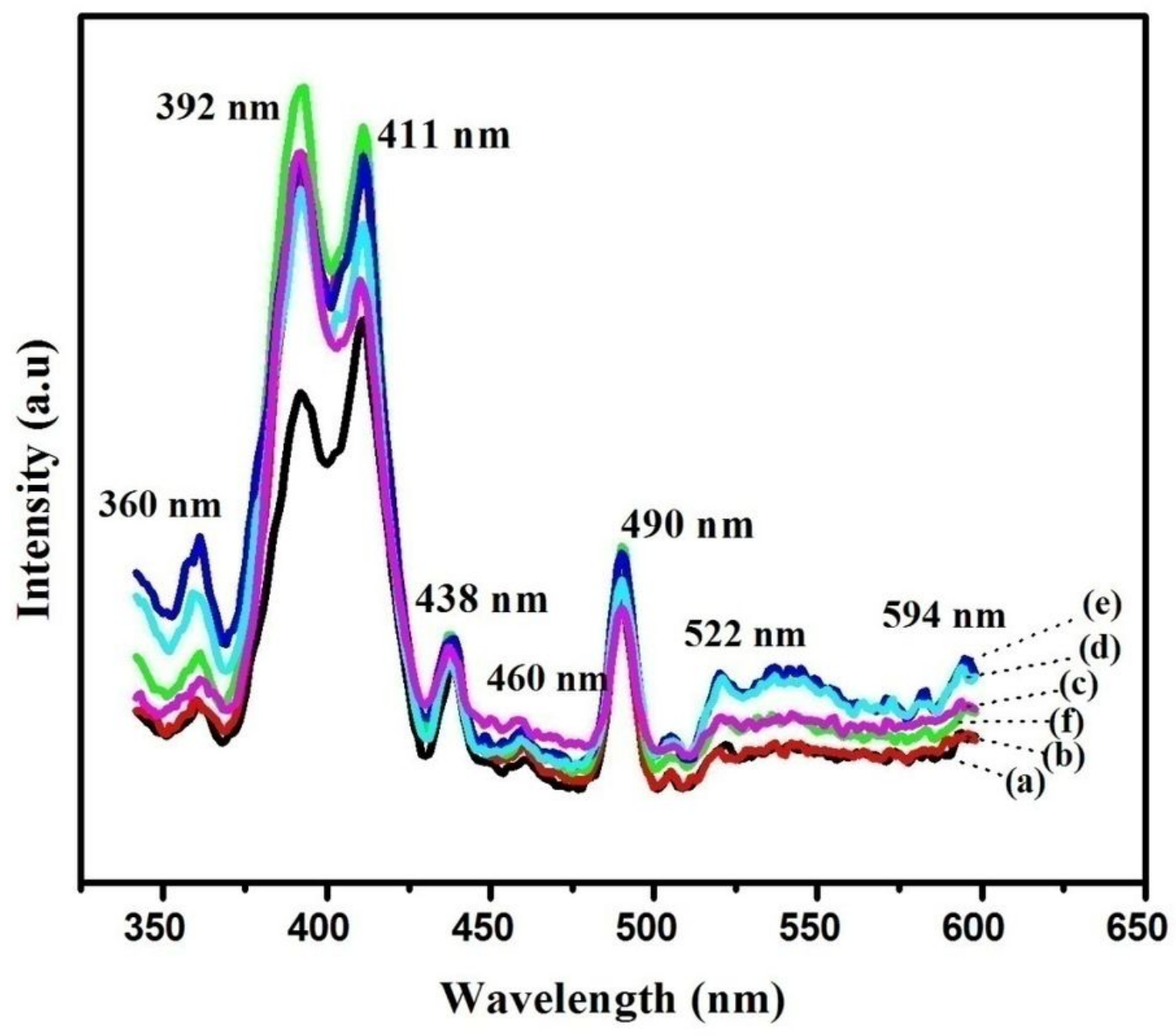

Figure 11

(A-F) Photoluminescence spectra of yttrium $(0.0,0.5,1.0,1.5,2.0$ and $2.5 \mathrm{mM})$ doped ZnO nanoparticles 


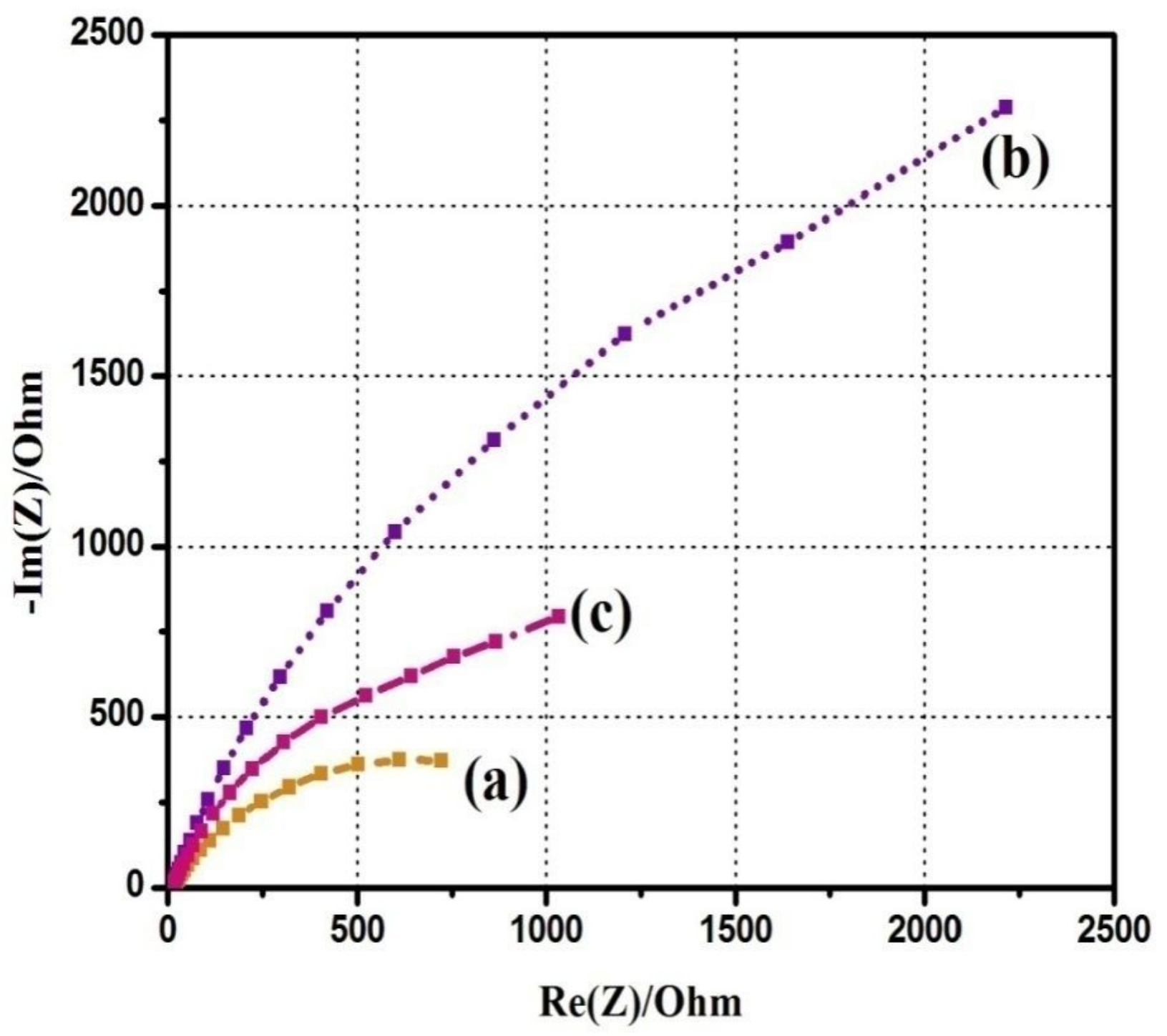

Figure 12

Nyquist plots of (A) $0.05 \mathrm{wt} \%$ (B) $0.10 \mathrm{wt} \%$ and (C) $0.15 \mathrm{wt} \%$ YZO/epoxy nanocomposite coated mild steel substrates in $\mathbf{3} \mathrm{wt} \% \mathrm{NaCl}$ solution after $\mathbf{2}$ hour immersion 


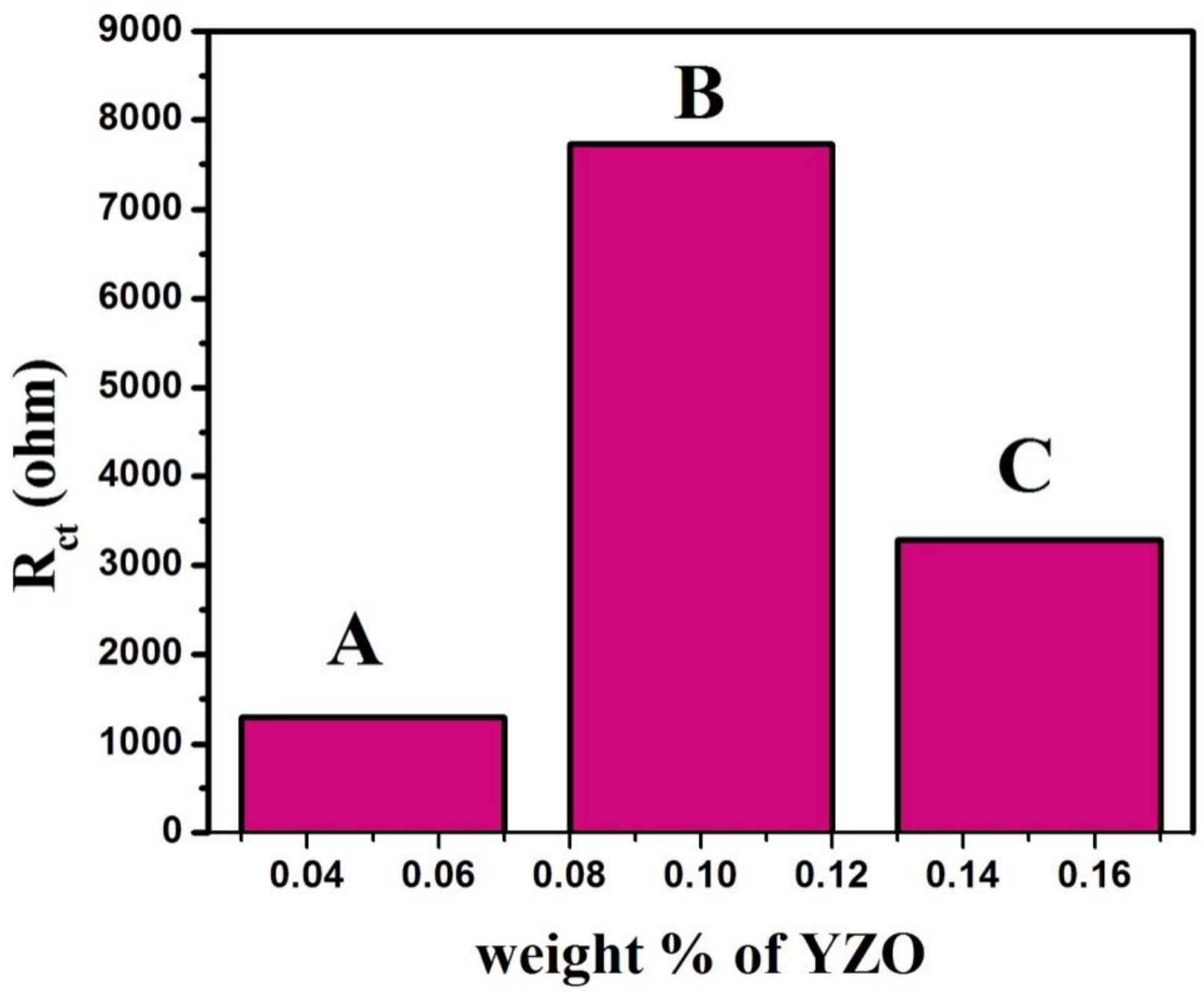

Figure 13

Variation in $\mathbf{R}_{\mathrm{ct}}$ versus weight percentage of $\mathrm{YZO}$ nanoparticles 


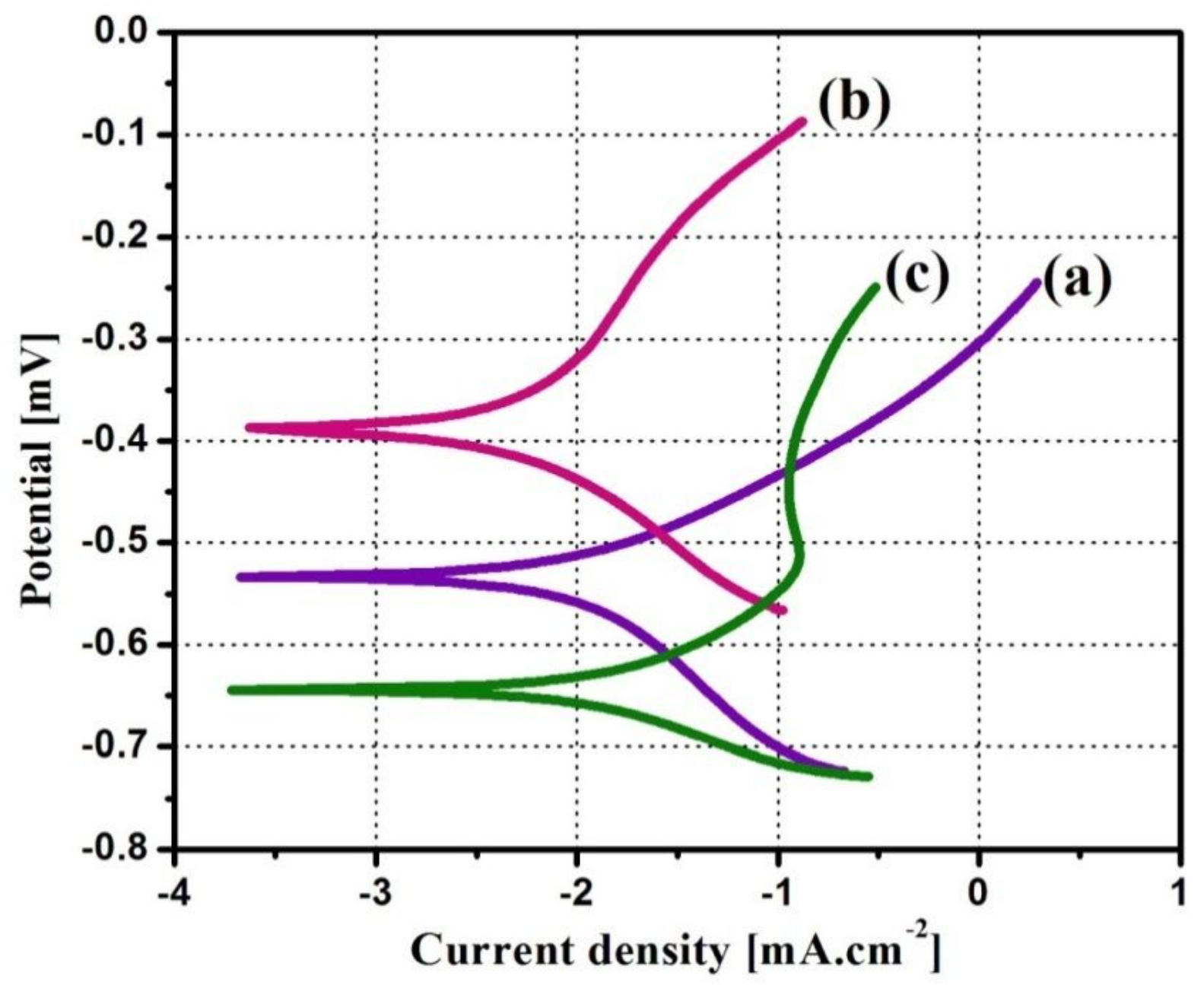

Figure 14

Tafel plots of (A) $0.05 \mathrm{wt} \%$ (B) $0.10 \mathrm{wt} \%$ and (C) $0.15 \mathrm{wt} \%$ YZO/epoxy nanocomposite coated mild steel substrates in $3 \mathrm{wt} \% \mathrm{NaCl}$ solution after 2 hour immersion 


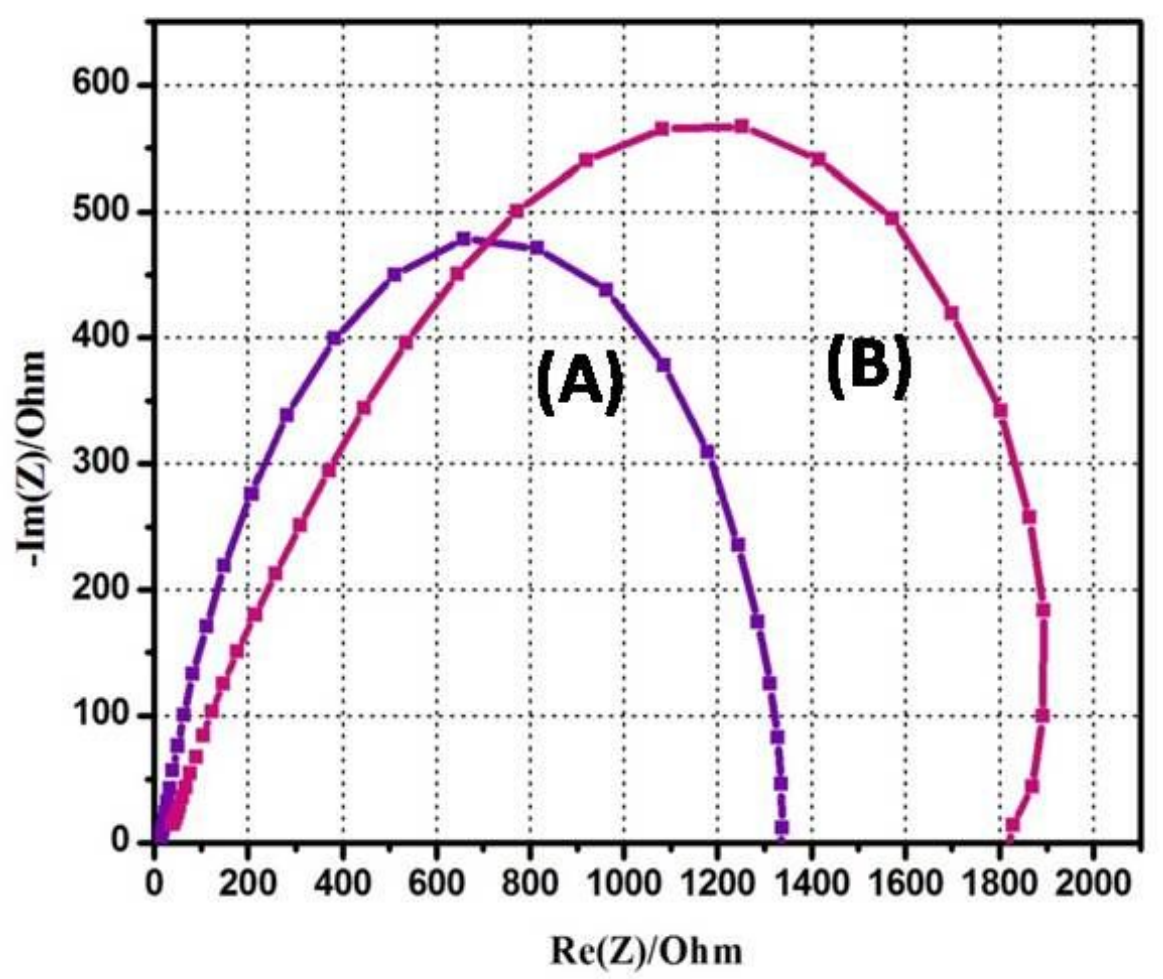

Figure 15

Nyquist plots of (A) $0.10 \mathrm{wt} \%$ epoxy/ZnO (B) $0.10 \mathrm{wt} \%$ epoxy/ YZO nanocomposite coated mild steel substrates in 3 wt $\%$ oxalic acid solution after 2 hour immersion 


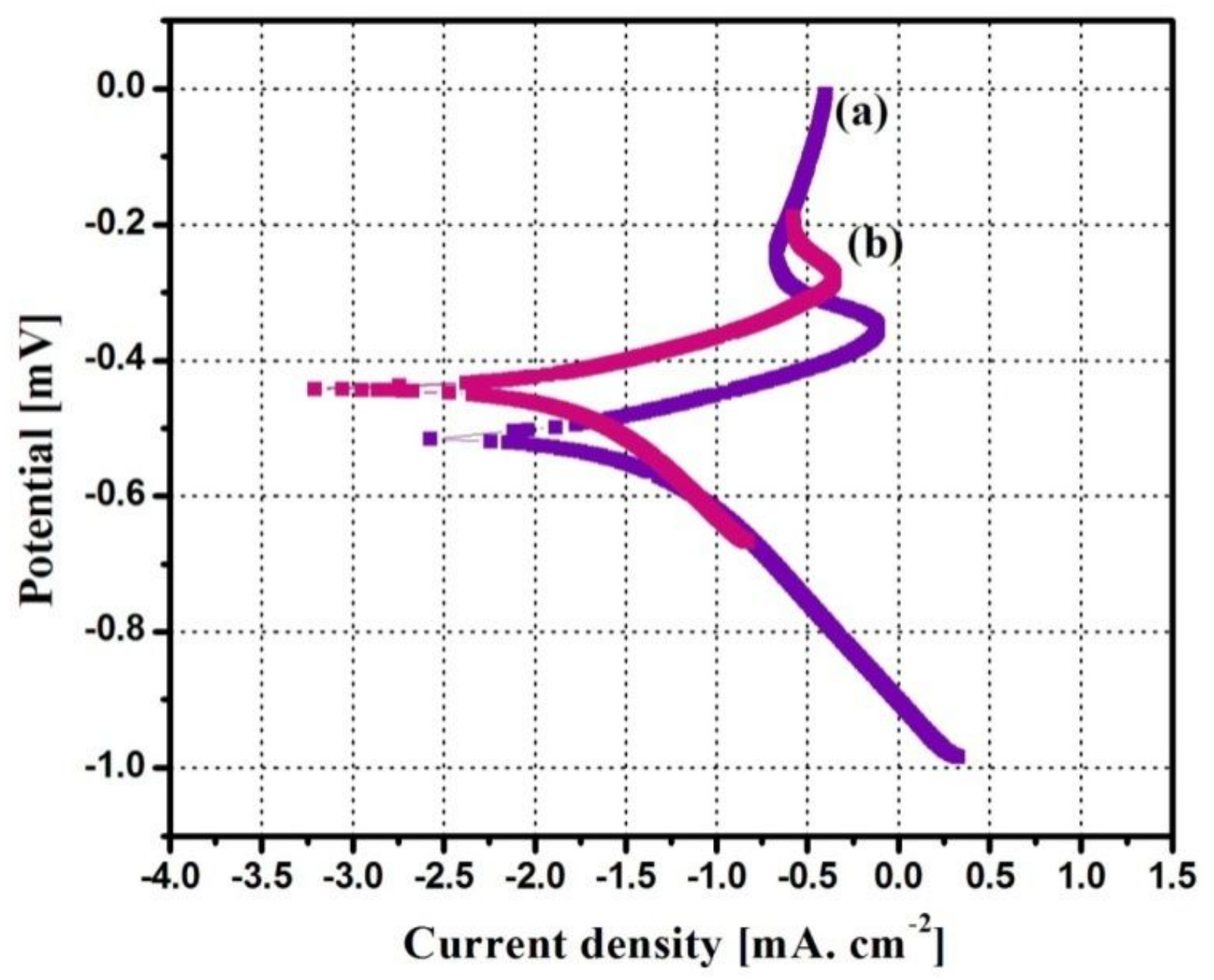

Figure 16

Tafel plots of (A) $0.1 \mathrm{wt} \%$ epoxy/ZnO (B) $0.1 \mathrm{wt} \%$ epoxy/YZO nanocomposite coated mild steel substrates in 3 wt \% Oxalic acid solution after 2 hour immersion 


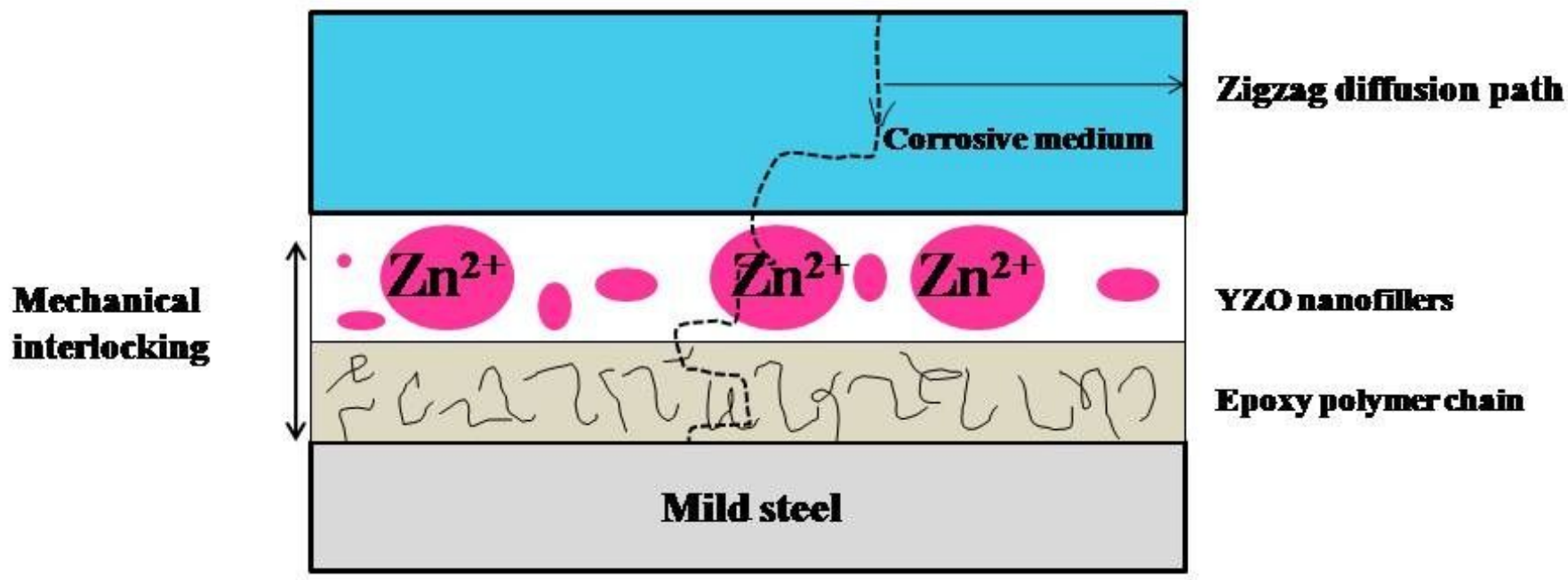

Figure 17

Hierarchy of corrosion protection mechanism of epoxy/YZO nanocomposite on mild steel 


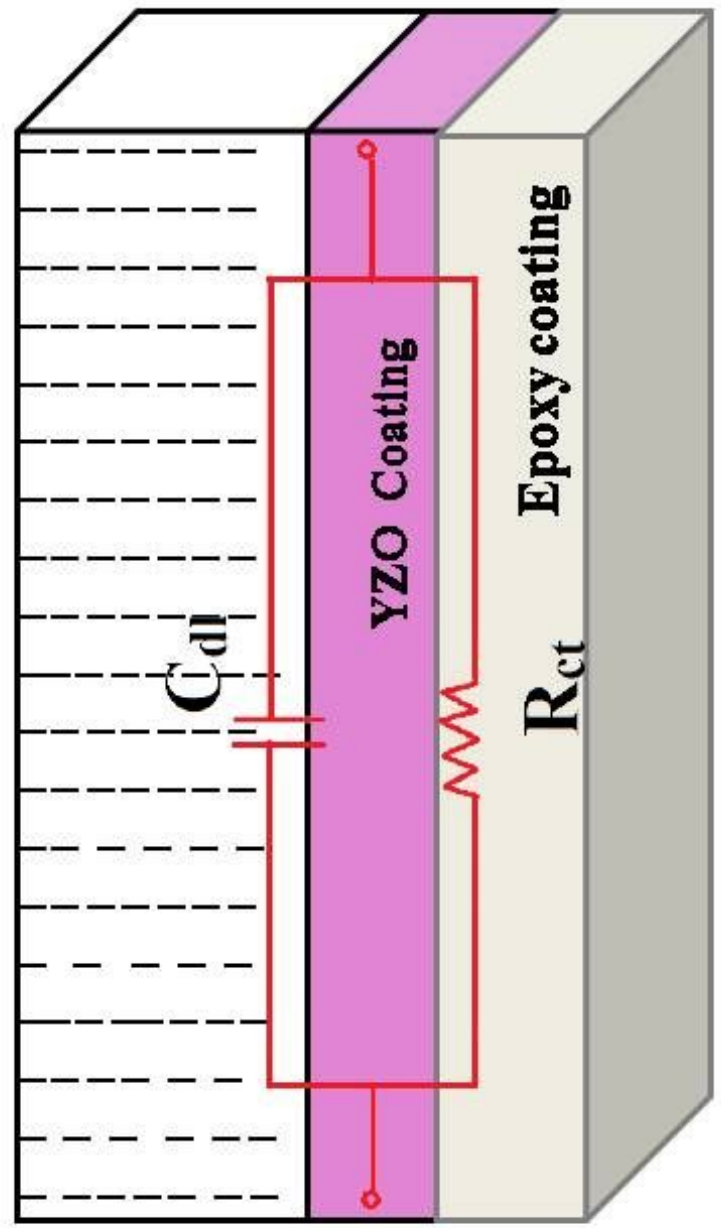

$\mathbf{R}_{\mathrm{et}}$ - Charge transfer resistance

$C_{\mathrm{dl}}$ - Double layer capacitance

Figure 18

Equivalent circuit model for epoxy/YZO nanocomposite coating on mild steel 


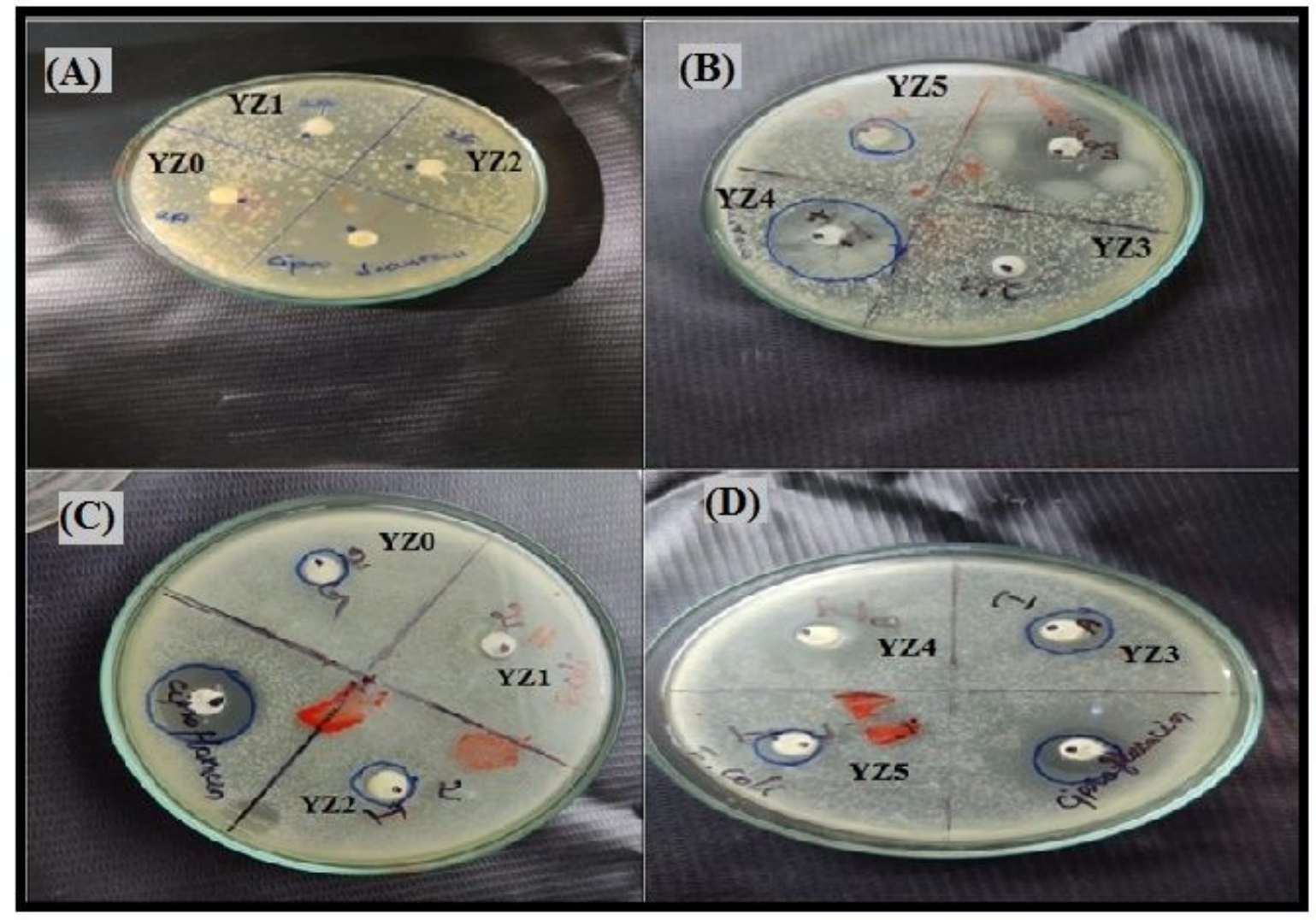

Figure 19

Antibacterial activity of yttrium $(0.0,0.5,1.0,1.5,2.0$ and $2.5 \mathrm{mM})$ doped $\mathrm{ZnO}$ nanoparticles against gram positive bacteria (A-B) and gram negative bacteria (C-D) 


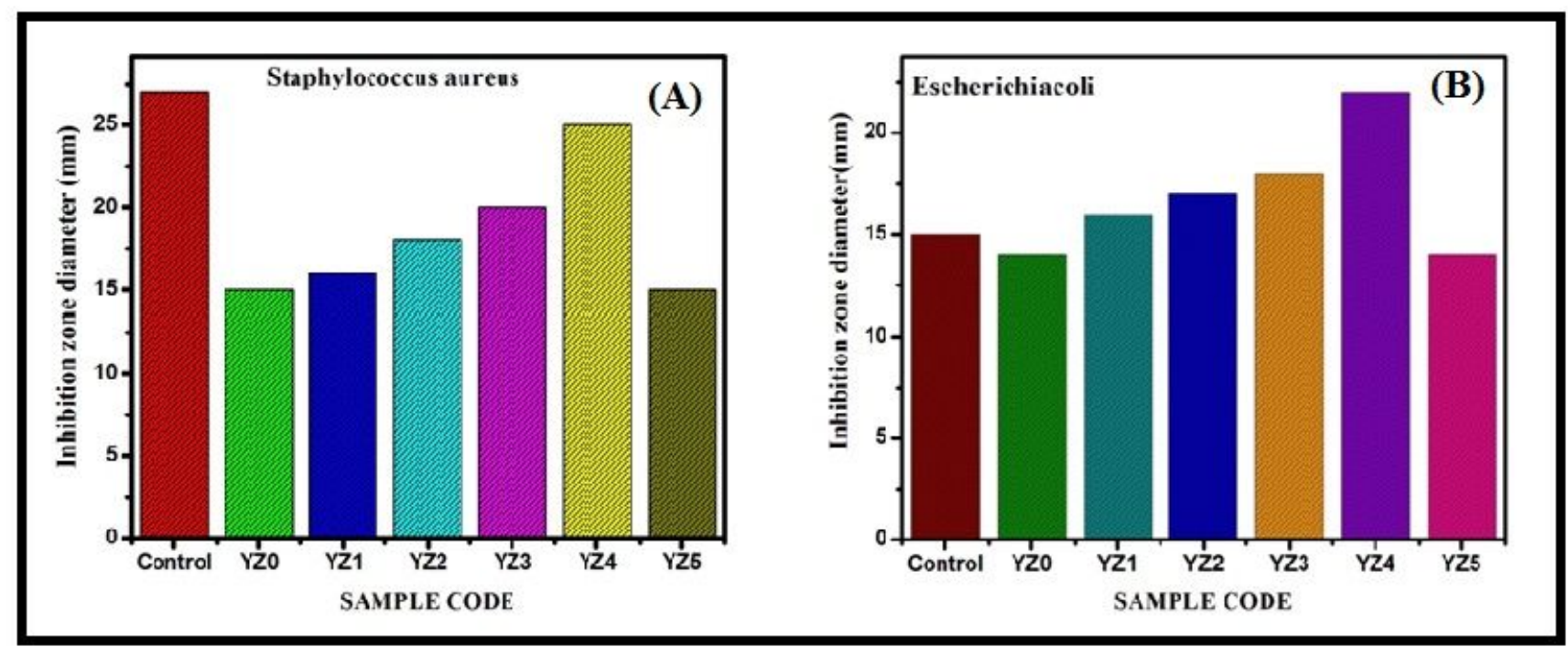

Figure 20

Graphical representation of zone of inhibition $(\mathrm{mm})$ of $(0.0,0.5,1.0,1.5,2.0$ and $2.5 \mathrm{mM})$ doped ZnO nanoparticles 